\title{
Relationship between Inflation and Monetary Indicators of Mongolia
}

Ulziideleg T* $^{*}$

Supervision Department, Bank of Mongolia (the Central Bank), Ulaanbaatar, Mongolia

\begin{abstract}
Including quarterly data from 1994-2004, and based on the classical theory of money policy and several empirical research, we have modelled the econometric model that indicate the relationship between money supply, exchange rate and inflation via $\mathrm{CPI}$ in the case of Mongolia. A series of tests have been done regarding to the true model. A positive finding is that the money supply and exchange rate have highly effects on inflation. This result may be developed in further study for the inflation targeting policy in Mongolia.
\end{abstract}

Keywords: Mongolia; Inflation; Economy, Market; Money

\section{Introduction}

Every day, the world concerns about inflation. Many controversies were raised in order to solve for the issues of inflation such as causes of inflation, whether the inflation has negative or positive effects on economy, and how the government can control it though monetary policie etc. Mongolia has undergone dramatic changes during its transition to a market economy, with fundamental restructuring in both the real economy and the financial sector. The policy of Mongolia's monetary authorities has been to keep the growth rate of the money supply stable while dealing with these transition-specific challenges as they occur. In addition, because of Mongolia's climate, which is characterized by extremes of temperature, the Mongolian economy is highly seasonal, and the authorities have occasionally intervened in the foreign exchange market to avoid excessive exchange rate fluctuations stemming from large, weather-related swings in exports and imports. Such a pragmatic approach to monetary policy has been necessary in many transition economies. Therefore, in order to analyse the role of policies during the translation the study will examine the relationship between the monetary policies-though monetary indicators, and the inflation by the establishment of inflation model.

\section{Literature Review}

When one turns to a discussion of the causes of inflation in developing countries one finds that the literature contains two major competing hypotheses which attempt to explain the phenomenon. First, there is the monetarist model, which sees inflation as a monetary phenomenon, the control of which requires a control of the money supply as a necessary and sufficient condition such that it grows at a rate consistent with the growth of demand for money with stable prices. The monetarist model is predicated upon the existence of a stable demand for money. An existence of stable demand for money in Mongolia itself might be a disputable proposition due to the numerous deep structural changes, which are underway within Mongolian economy since 1990.

Another model is structural list model, by contrast, argues that the causes of inflation must be sought in certain structural characteristics of developing countries which make them particularly inflationprone and that elimination of inflation requires that policy be directed toward removing the various bottlenecks which are said to initiate and perpetuate inflation.

Several researches have been set up in sphere of monetarist model. According to Mankiw [1], inflation is simply an increase in overall level of prices, and this can be express in term of money exchange equation: GDP (Y)
Or $\mathrm{V}=\mathrm{Y} / \mathrm{M}=\left(\mathrm{P}^{\star} \mathrm{Q}\right) / \mathrm{M}$

Of which: $Q$ is the total number of items purchased during period of time $\mathrm{P}$ is the average price level for the economy during period of time.

If $\mathrm{V}$ and $\mathrm{Q}$ are constant, then we can state the equation of exchange in terms of rates of growth:

The rate of growth of the money supply=the inflation rate.

Intuitionally the economy's overall level of price can be look at the price of a basket of goods and services or in other way, it measures the value of money. Because money is used in virtually all economic transactions, it has a powerful effect on economic activity. An increase in the supply of money puts more money in the hands of consumers, making them feel wealthier, thus stimulating increased spending. Business firms respond to increased sales by ordering more raw materials and increasing production. The spread of business activity increases the demand for labour and raises the demand for capital goods. In a buoyant economy, stock market prices rise and firms issue equity and debt. If the money supply continues to expand, prices begin to rise, especially if output growth reaches capacity limits. As the public begins to expect inflation, lenders insist on higher interest rates to offset an expected decline in purchasing power over the life of their loans. Inflation sometimes is defined informally as "too much money chasing too few goods." [2]. This statement implied that a rise in the price level means a lower value of money because now people have to pay more for smaller quantity of good and services. The statement also captures important aspects of why money growth is related to inflation. Still, it is better to define inflation as increases in the general level of prices rather than in terms of why increases in the general price level occur. In the researcher, Rolnick and Weber found that there were extremely high correlation between money growth and inflation [3]. Moreover, they also indicated that the strength of the relationship does not vary with the measure of money used. The correlation between money growth, measured by primary money, secondary money, or M2, and inflation

*Corresponding author: Ulziideleg T, Senior Supervisor, Supervision Department, Bank of Mongolia (the Central bank), Ulaanbaatar, Mongolia, Tel: + 976-11-327093; E-mail: taivan@mongolbank.mn

Received November 13, 2017; Accepted November 18, 2017; Published December 26, 2017

Citation: Ulziideleg T (2017) Relationship between Inflation and Monetary Indicators of Mongolia. Bus Eco J 8: 332. doi: 10.4172/2151-6219.1000332

Copyright: @ 2017 Ulziideleg T. This is an open-access article distributed under the terms of the Creative Commons Attribution License, which permits unrestricted use, distribution, and reproduction in any medium, provided the original author and source are credited. 
is always 0.99 . That shows the linear relation between monetary growth and inflation. By the research in Gan-Ochir considered monetary factors that influence inflation. Consequently, he has established the relationship between the monetary aggregates and did prediction of inflation rate in the next years. Other research by Bathsukh was also set up the dynamic model to forecast the change in inflation rate based on monetary growth.

In addition, exchange rate is also considered as one of factors affects inflation. Basically, the exchange rate measures the price of one currency in term of others. In the very short term, it is the only variable explaining inflation directly or in other words, if the exchange rate changes, businesses immediately react by adjusting domestic prices. Torsten found that the exchange rate has a significant effect on inflation during all time periods examined in Mongolia [4]. The country's experiences seasonal movements in the exchange rate, which, if left unsmoothed, could have undesirable effects on inflation An another research done by Siliverstovs and Bilan in Ukraine also shows that there is a close link between exchange rate development and inflation [5]. In fact, in all cases, reduction of inflation was due to lower import prices. The credibility the Bank of Mauritius has recently established with its 'inflation targeting lite' regime has allowed it to shift from an emphasis on exchange rate targeting towards inflation targeting.

This paper will develop a macro finance model for the inflation case, allowing the investigation of Mongolia experience with inflation targeting as described. By estimating a model in which the yield curve is modelled explicitly we are able to obtain estimates of inflation expectations $[6,7]$.

\section{Methodology}

In this study, in order to analyse the phenomenon of inflation in case of Mongolia, firstly, we will do the secondary research to develop our theory that is a base for building the model. The method of Ordinary Least Square (OLS) is employed basing on the statistics and data from the IMF to estimate our built model.

Data used in this study are quarterly spanning 1995-2004 (including 40 data points or observations) that sourced from IMF. We start with the year 1995 as it was marked by relative stabilization of macroeconomic indicators compared to severe economic decline and hyper nation observed in earlier periods.

Basing on our discussion from the above, we could therefore choose the following variables: Consumer price index, $\mathrm{CPI}_{\mathrm{t}}$ that reflects the change in average level of prices

\section{Exchange rate, in logs: LnExt (\$Togrogs/\$US)}

Money supply: narrow money M1 and broad monetary aggregate M2, in logs: LM1t, LM2t respectively (millions of Togrogs end of the period).

And our model will be: $\mathrm{CPI}_{\mathrm{t}}=\gamma_{0}+\gamma_{1} \ln (\mathrm{MI})_{\mathrm{t}}+\gamma_{2} \ln (\mathrm{M} 2) \mathrm{t}+\gamma_{3} \ln (\mathrm{Ex})_{\mathrm{t}}+\mathrm{u}_{\mathrm{t}}$

Practically, in term of studying the relationship between money supply, exchange rate and inflation, the Lin-Log model will be able to express the percent growth in inflation of Mongolia (via CPI) for an absolute change in money supply and exchange rate as well. Let us interpret the slope coefficient:

$$
\gamma_{i}=\frac{\text { Change ininflation }}{\text { Change in } \operatorname{Ln}(M, E x)}=\frac{\text { Change in } Y}{\text { Relatieve change in } X} .
$$

\section{Results}

Assume that we have already constructed the true model which expresses the effects of money supply and exchange rate on inflation in Mongolia as discussed above:

$$
\mathrm{CPI}_{\mathrm{t}}=\gamma_{0}+\gamma_{1} \ln (\mathrm{MI})_{\mathrm{t}}+\gamma_{2} \ln (\mathrm{M} 2) \mathrm{t}+\gamma_{3} \ln (\mathrm{Ex})_{\mathrm{t}}+\mathrm{u}_{\mathrm{t}} .
$$

Now, we start running the regression for our model. The results will give as (Appendix 1):

$\mathrm{CPI}=-444.9306351+10.0572671^{\star} \mathrm{LNM} 1+8.400272755^{\star} \mathrm{LNM} 2+46$. $1229659^{*}$ LNEX

$$
\begin{aligned}
& \mathrm{Se}=(13.27225)(6.467621)(4.175690)(5.160813) \\
& \mathrm{t}=\quad(-33.52337)(1.555018)(0.0518) \quad(8.937150) \\
& \mathrm{P}=\left(\begin{array}{llll}
(0.0000) & (0.1287) & (0.0000) & (0.0000)
\end{array}\right.
\end{aligned}
$$

R-squared $=0.979083 ; n=40 ;$ F-statistic $=561.7073$.

Interpreted in the manner described earlier the equation states that an increase in money supply or exchange rate of 1 percent, on average, leads to about $0.10 \mathrm{M} 1 ; 0.84 \mathrm{M} 2$ and 4.61 increases respectively.

\section{Test for multicollinearity}

From the estimated results we can see that R2 is high (0.979083) and positive coefficients of predictors. However, these regressors log (M1) and $\log$ (M2) are statistically insignificant t-test. Thus, we should suspect that those two variables may be mutually correlated. Generally there is no exactly linear relationship among the estimated variables, especially in data involving economic time series. In our case, the less perfect multi collinear between the variable can be expressed as:

$\log M 2_{t}=\lambda^{\star} \log M 1_{t}+v_{t}$

Where $v_{\mathrm{i}}$ is a stochastic error

To find out the problem, we firstly carry out a pair-wise correlation. It can be shown in Table 1.

It is clearly seen that correlation between M1 and M2 (r12 exceeds 0.9 ) is too high that will cause large variance because:

$$
\operatorname{Cov}(\hat{\gamma} 1, \hat{\gamma} 2)=-r_{12}^{2} * \delta^{2} /\left(1-r_{12}^{2}\right) * \sqrt{\sum x_{l i}{ }^{2} \sum x_{2 i}{ }^{2}}
$$

As co-linearity increases, the covariance of two estimators increases, and reaches infinity as $\mathrm{r} 12=1$. Thus, then multicollinearity is serious problem. To solve the problem, we will drop one variable out of the model.

Actually, from the critical study in term of macroeconomics in the previous section, we know that M2 is broad money which includes M1. This might be a main cause of multicollinearity. We therefore get M1 out of our model, and our new model can be shown as:

$C \hat{P}_{t}=\gamma+\gamma_{1} \ln (M 2)_{t}+\gamma_{2} \ln (E x)_{t}+u_{t}$

With the new model, we run the regression and a result given in the Appendix 2

$\mathrm{CPI}=-444.1762526+52.06044786^{*} \mathrm{LNEX}+14.46126832^{\star} \mathrm{LNM} 2$

\begin{tabular}{|c|c|c|c|c|}
\hline & LNM2 & LNM1 & LNEX & CPI \\
\hline LNM2 & 1 & 0.97 & 0.82 & 0.92 \\
\hline LNM1 & 0.97 & 1 & 0.9 & 0.96 \\
\hline LNEX & 0.82 & 0.9 & 1 & 0.96 \\
\hline CPI & 0.92 & 0.96 & 0.96 & 1 \\
\hline
\end{tabular}

Table 1: The pair-wise correlation between variables. 


$$
\begin{aligned}
& \mathrm{Se}=(13.50161) \\
& \mathrm{t}=(-32.89803) \\
& \mathrm{P}=(0.0000)
\end{aligned}
$$

$(1.607987)$

(8.993398)

(0.0000)
R-squared $=0.979083 ; \mathrm{n}=40 ; \mathrm{F}$-statistic $=811.8012$.

The results show that after getting M1 out of the model, the standard errors are quite small in comparison with its coefficients. $t$ values are large and $\mathrm{P}$ values equal to zero that both are significant. However, the DW indicator is a bit small. It might tell us about autocorrelation.

\section{Test for autocorrelation}

From the regression, we see that the Durbin-Watson stat is not much significant $(\mathrm{d}=1.335499)$. That result might make us be suspect that there is an autocorrelation. This phenomenon means that the error terms are interrelated - that is, prior error information influences the value of the current error term. The current error term can be written as some function of previous error terms:

$$
\mathrm{u}_{\mathrm{t}}=\alpha \mathrm{u}_{\mathrm{t}-1}+\mathrm{v}_{\mathrm{t}}
$$

Thus, for more precise we will look at the residual's graph (Figure 1).

The graph tells us that CPI of previous period also affects the next period and that will occur over time.

Breusch-Godfrey test: However, to avoid some pitfalls of the Durbin-Watson test, we will apply the Breusch-Godfrey (BG) test of autocorrelation that is general in the sense of allowing for nonstochastic regressors such as the lagged value of regression. This lagged value can be then added to the model.

Recall the model: $C \hat{P} I=\gamma+\gamma_{1} \ln (M 2)_{t}+\gamma_{2} \ln (E x)_{t}+u_{t}$ and assume the error term $u_{t}$ follows the $p_{t h}$-order autoregressive, AR $(p): u_{t}=\rho_{1} u_{t}$ ${ }_{1}+\rho_{2} \mathrm{u}_{\mathrm{t}-2}+\ldots .+\rho_{\mathrm{p}} \mathrm{u}_{\mathrm{t}-\mathrm{p}}+\varepsilon_{\mathrm{t}}$.

To treat this problem, we will put lagged variable in our model. The new model then will be:

$$
\mathrm{CPI}_{\mathrm{t}}=\gamma_{0}+\gamma_{1} \ln (\mathrm{MI})_{\mathrm{t}}+\gamma_{2} \ln (\mathrm{M} 2) \mathrm{t}+\gamma_{3} \ln (\mathrm{Ex})_{\mathrm{t}}+\mathrm{AR}(1)+\mathrm{u}_{\mathrm{t}}
$$

Based on the new model, we run the regression to obtain the result as:

$\mathrm{CPI}=-428.7244058+47.45893757^{\star} \mathrm{LNEX}+15.76219538^{\star} \mathrm{LNM} 2+[$ $\operatorname{AR}(1)=0.3118824325$ ]

$$
\begin{array}{lllll}
\mathrm{Se}= & (21.21859) & (5.194420) & (2.177666) & (0.158977) \\
\mathrm{t}= & (-20.20513) & (9.136522) & (7.238113) & (1.961804) \\
\mathrm{P}= & (0.0000) & (0.000) & (0.0000) & (0.0578)
\end{array}
$$

R-squared $=0.977752 ; n=39 ;$ F-statistic $=512.7198 ; \mathrm{d}=1.843902$.

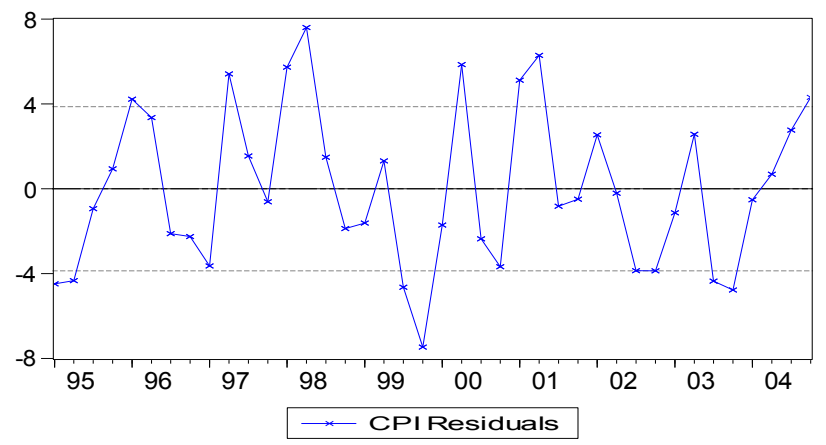

Figure 1: Residuals graph
Under the null hypothesis of no serial autocorrelation: $\mathrm{H}_{0}: \rho_{1}=\rho_{2}=0$, then we now calculate the BG: $(n-p) R^{2} \approx X_{p}^{2}$ based on our output of BG serial autocorrelation (Appendix 3).

$(\mathrm{n}-\mathrm{p}) \mathrm{R}^{2}=(40-1) \times 0.0712598=2.779132$

Choose $\alpha=5 \%$, we have $X_{1}^{2}=3.84146>(n-p) * \mathrm{R}_{2}=2.779132$, thus we fail to reject the null hypothesis of no serial autocorrelation and obviously there is no need to consider more than one lag.

Durbin Watson test: The new model with Durbin-Watson stat. $\mathrm{d}=1.843902$ is close to 2 that mean we can confidently say that there may be slightly positive autocorrelation (Appendix 4)

With 39 observations and three explanatory variables (excluding the intercept term), we will have a significant points of $\mathrm{d}_{\mathrm{L}}$ and $\mathrm{d}_{\mathrm{U}}$ at $5 \%$ significant level as: $\mathrm{d}_{\mathrm{L}}=1.137 \mathrm{~d}_{\mathrm{U}}=1.453$.

Assume: $\mathrm{H}_{\mathrm{o}}: \sigma=0$ versus $\mathrm{H}_{1}: \sigma \neq 0$, and

$\mathrm{d}_{\mathrm{U}}=1.453<\mathrm{d}=1.843902<4-\left(\mathrm{d}_{\mathrm{U}}=1.453\right)$

$\mathrm{d}_{\mathrm{U}}=1.453<\mathrm{d}=1.843902<2.547$ that, there is statically significant evidence of no autocorrelation either positive of negative.

Run test: In order to ensure our results we should carry out another test. Then Run Test will be employed as (Table 2):

$\mathrm{N}_{1}=20$ : number of positive signs (+ residuals); $\mathrm{N}_{2}=20$ : number of negative signs (- residuals)

$\mathrm{N}$ : total number of observations $=\mathrm{N}_{1}+\mathrm{N}_{2}=40 ; \mathrm{R}=16$ : number of runs

Thus, Mean $E(R)=\frac{2 N_{1} N_{2}}{N}+1=\frac{2 * 20 * 20}{40}+1=21$

And variance $\sigma_{R}^{2}=\frac{2 N_{1} N_{2}\left(2 N_{1} N_{2}-N\right)}{N^{2}(\mathrm{~N}-1)}=\frac{2 * 20 * 20 *(2 * 20 * 20-40)}{40^{2} *(40-1)}=9.7436$.

Now we construct the probability of $95 \%$ that the preceding interval will include R:

$$
\begin{aligned}
& \operatorname{Pr}\left[E(R)-1.96 \times \sigma_{R} \leq R \leq E(R)+1.96 \times \sigma_{R}=0.95\right. \\
& \Rightarrow>\operatorname{Pr}\left[21-1.96^{\star} 3.1215 \leq R \leq E(R)+1.96^{*} 3.1215=0.95\right. \\
& \Rightarrow \operatorname{Pr}[14.8819 \leq R \leq 27.1181=0.95 .
\end{aligned}
$$

It is clearly seen that $\mathrm{R}$ falls inside the interval that means the null hypothesis of randomness is satisfied. We then ensure that there is no autocorrelation in our model.

\section{Test normality of the error term}

The Jarque-Bera is a test of normality that is actually based on the

\begin{tabular}{|c|c|c|c|c|c|c|c|c|}
\hline Residuals & $+/-$ & Runs & Residuals & $+/-$ & Runs & Residuals & $+/-$ & Runs \\
\hline-4.8528 & - & 1 & 1.2568 & + & 6 & 2.5433 & + & 12 \\
\hline-3.9983 & - & 1 & -2.0682 & - & 7 & 1.349 & + & 12 \\
\hline-1.1564 & - & 1 & -4.3533 & - & 7 & -3.2445 & - & 13 \\
\hline 0.9175 & + & 2 & 0.9769 & + & 8 & -3.3716 & - & 13 \\
\hline 4.3353 & + & 2 & -4.8388 & - & 9 & -1.5395 & - & 13 \\
\hline 3.9813 & + & 2 & -7.0217 & - & 9 & 3.3382 & + & 14 \\
\hline-1.1111 & - & 3 & -1.312 & - & 9 & -4.2132 & - & 15 \\
\hline-1.9032 & - & 3 & 7.6848 & + & 10 & -5.6327 & - & 15 \\
\hline-5.5244 & - & 3 & -0.863 & - & 11 & -1.8285 & - & 15 \\
\hline 5.1231 & + & 4 & -3.0439 & - & 11 & 0.7297 & + & 16 \\
\hline 1.7559 & + & 4 & 4.9077 & + & 12 & 2.0137 & + & 16 \\
\hline-1.1077 & - & 5 & 7.4473 & + & 12 & 2.4997 & + & 16 \\
\hline 4.0432 & + & 6 & 0.0545 & + & 12 & & & \\
\hline 7.6305 & + & 6 & 0.3965 & + & 12 & & & \\
\hline
\end{tabular}

Table 2: Autocorrelation run test. 
OLS residuals. The JB test is valued at:

$$
J B=n *\left[\frac{S^{2}}{6}+\frac{(\mathrm{K}-3)^{2}}{24}\right] \cdot
$$

Where $\mathrm{K}=$ Kurtosis coefficient, and $\mathrm{S}$ is Skewness. For normality $\mathrm{S}=0$ and $\mathrm{K}=3$. Therefore the value of JB test is expected to be zero. By using review, we have obtained a result as Figure 2.

The Jarque-Bera statistic is 2.81459 and the p-test is large, so we cannot reject the null of normality. If the $\mathrm{p}$-statistic was very low $(0.05$ and below) we could reject the null of normality. The magnitude of the JB test is not large - it is a function of the sample size, and there are 51 observations so this is quite a reasonable (Figure 2). The Kurtosis is close to 3 , and the Skewness is close to 0 , and the observed histogram is reasonably bell-shaped. We can be quite comfortable that the residuals are essentially normally distributed.

\section{Heteroskedasticity test}

Recall that one of the important assumptions of the classic linear regression model is that the variance of each disturbance term $U_{i}$, conditional on the chosen values of the explanatory variables, is some constant number equal to $\sigma^{2}$. Symbolically, it can be expressed as:

$$
E\left(u_{i}^{2}\right)=\sigma^{2}, i=1,2,3 \ldots . . n
$$

With this assumption of homoskedasticity, our OLS will be BLUE. Thus, to ensure whether our model satisfies the assumption or not, it is very necessary to check heteroskedasticity. Actually, this phenomenon is that the conditional variance of $\mathrm{Yi}$ is not a constant. It increases as explanatory $\mathrm{Xij}$ increases that means:

$$
E\left(u_{i}^{2}\right)=\sigma_{1}^{2}, i=1,2,3 \ldots . . n \text {. }
$$

Actually, if our model is heteroskedasticity, it may cause series of problems such as unbiased estimating of coefficients of explanatory variables, unnecessarily larger confidence interval. As consequence, a result of t-test and F-test will statistically be incorrect. To cope with the problem, there are several test can be employed to test our model whether there is heteroskedasticity in the data.

White's general heteroskedasticity test: This method requires reordering the observations with respect to the $\mathrm{X}$ variable that supposedly caused heteroskedasticity. Generally, it is widely used as it does not rely on the normality assumption and easily to implement. By applying the method to the residuals obtained from regression, we have the following result (Appendix 5) (Table 3).

Under the null hypothesis that there is no heteroskedasticity, we have $\mathrm{n}^{\star} \mathrm{R}^{2}$ follows the $X^{2}{ }_{d f}$ distribution:

$$
n * R^{2} \sim X_{d f}^{2}=0.109614 * 39=4.274946
$$
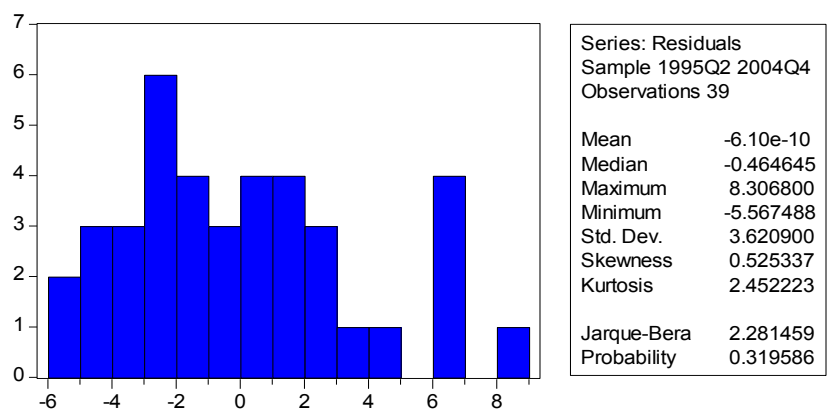

Figure 2: Linear relationship between $\mathrm{M} 2$, exchange rate and $\mathrm{CPI}$.

\begin{tabular}{|l|c|c|c|c|}
\hline F-statistic & 0.815692 & \multicolumn{2}{|c|}{ Probability } & 0.547174 \\
\hline Obs*R-squared & 4.289823 & \multicolumn{2}{|c|}{ Probability } & 0.508487 \\
\hline Variable & Coefficient & Std. Error & t-Statistic & Prob. \\
\hline C & 4073.239 & 6137.111 & 0.663706 & 0.5115 \\
\hline LNEX & -297.563 & 726.8197 & -0.40941 & 0.6849 \\
\hline LNEX^2 & -106.875 & 138.8841 & -0.76953 & 0.4471 \\
\hline LNEX*LNM2 & 147.6774 & 175.6612 & 0.840694 & 0.4066 \\
\hline LNM2 & -507.066 & 750.9706 & -0.67521 & 0.5042 \\
\hline LNM2^2 & -21.2381 & 23.76528 & -0.89366 & 0.378 \\
\hline R-squared & 0.109995 & \multicolumn{2}{|c|}{ Mean dependent var } & 12.73883 \\
\hline
\end{tabular}

Table 3: General heteroskedasticity test.

Choose the critical chi_square value for $5 \mathrm{df}$, we have: for $5 \%$, $X_{d f=5}^{2}=11.0705>n * R^{2}$

$$
\begin{aligned}
& \text { for } 10 \%, X_{d f=5}^{2}=9.2363>n * R^{2} \\
& \text { for } 25 \%, X_{d f=5}^{2}=6.62568>n * R^{2} .
\end{aligned}
$$

Thus, for all our practical purposes, we can conclude that there is no heteroskedasticity in our data.

Goldfeld-Quandt test: This is also a popular method that is applicable if one as assumes the heteroskedastic variance, $\sigma_{i}^{2}$ is positive related to one of the explanatory variables in the regression model. Suppose $\sigma_{i}^{2}$ is positive related to exchange rate and money supply as:

$\sigma_{i}^{2}=\sigma^{2} * X_{i}^{2}$

Then, we, in turn, rank exchange rate and money supply as:

Before ranking, we will choose c central observation. Empirically, our data has 40 observation, so $\mathrm{c}$ value will be 8 .

+Ranked by the exchange rate with the lowest $\mathrm{X}$ value, then omitting $c=8$ observations from central.

The regression based on the first 16 observations is:

$\mathrm{CPI}=-559.6518656+42.29864703^{\star} \mathrm{LNEX}+29.75274908^{\star} \mathrm{LNM} 2+[$ $\operatorname{AR}(1)=-0.0306494754]$

with RSS1=154.3905

The regression based on the last 16 observations is:

$\mathrm{CPI}=-1664.423233+266.3944239^{\star} \mathrm{LNEX}-7.478146541^{\star} \mathrm{LNM} 2+[$ $\operatorname{AR}(1)=-0.2160531046]$

with RSS2 $=124.9626$

From these results we obtain: $\lambda=\frac{R S S_{2} / d f}{R S S_{1} / d f}=\frac{154.3905 / 12}{124.9626 / 12}=1.235494$.

The critical $\mathrm{F}$ value for $12 \mathrm{df}$ of both numerator and denominator at 5 percent level is 2.69 , exceeds the estimated $F(\lambda)$. Thus, we may conclude that there is no heteroskedasticity in the error variance.

+ Ranked by the money supply, then omitting $c=8$ observations from central.

The regression based on the first 16 observations is:

$\mathrm{CPI}=-611.7827184+38.13089521^{\star} \mathrm{LNEX}+36.50800683^{\star} \mathrm{LNM} 2+[$ $\mathrm{AR}(1)=-0.329436164]$

with RSS $_{1}=125.20707$

The regression based on the last 16 observations is:

$\mathrm{CPI}=-1438.982408+227.4055316^{\star} \mathrm{LNEX}-3.749316657^{\star} \mathrm{LNM} 2+[$ $\mathrm{AR}(1)=-0.01690232852]$ 
with $\mathrm{RSS}_{2}=129.4435$

We also obtain: $\lambda=\frac{R S S_{2} / d f}{R S S_{1} / d f}=\frac{125.20707 / 12}{129.4435 / 12}=0.96727$

Similarity, at 5 percent level is 2.69 , the estimated $\mathrm{F}(\lambda)$ is smaller that means there is no heteroskedasticity in the error variance.

Sperman's rank correlation test: Apart from two test above, we also apply other test is Spearman's rank test. To do this, we firstly estimate the Spearman's rank correlation coefficient as: $r_{s}=1-6\left[\frac{\sum d_{i}^{2}}{n\left(n^{2}-1\right)}\right]$.

Where di is different in the ranks assigned to two different characteristics of $i_{\text {th }}$ individual and $n$ is the number of individual ranked. Run the regression to find $u_{i}$. Then, rank $u_{i}, m_{2}$ and ex, we have obtained the Table 4

As resulting in the table, we now calculate:

+Correlation coefficient between ui and exchange rate:

$r_{s}^{1}=1-6\left[\frac{11942}{40 *\left(40^{2}-1\right)}\right]=-0.0780488 \Rightarrow t=\frac{r_{s}^{*} \sqrt{n-2}}{\sqrt{1-r_{s}^{2}}}=\frac{-0.0780488 * \sqrt{40-2}}{\sqrt{1-(-0.0780488)^{2}}}=-0.482597138$.

Choose level of significant Choosing the significant level $\alpha=1 \%$, we have $\mathrm{t}_{\mathrm{c}}=\mathrm{t}_{0.05,38}=2.0315 \mathrm{It}$ is clearly seen that $t_{c}>$ computed $|t|$, thus there we may reject the null hypothesis of heteroskedasticity.

Similarity, we can obtain the correlation coefficient between $u_{i}$ and money supply:

$$
r_{s}^{\prime}=1-6\left[\frac{11996}{40^{*}\left(40^{2}-1\right)}\right]=-0.12532833 \Rightarrow t=\frac{r^{*} * \sqrt{n-2}}{\sqrt{1-r_{s}^{2}}}=\frac{-0.12532833 * \sqrt{40-2}}{\sqrt{1-(-0.12532833)^{2}}}=-0.778715637 \Rightarrow|t|<t_{c}=2.0315 .
$$

From the test, there is no evidence of systematic relationship between the explanatory and the absolute value of residual, which might suggest that there is no heteroskedasticity.

In fact, there is an another test, Breusch-Pagan-Godfrey, which may use to test the heteroskedasticity. However, strictly speaking, the BPG test is an asymptotic, large sample, test and in the present example 40 observations may not constitute a large sample. With three tests previously done, we can be confident to get out of the heteroskedasticity problem.

\section{Chow Test for Structure Stability}

Mongolia's experience has been different from that of most other transition countries. The country experienced a prolonged period of moderate inflation. Annual inflation fell below 10 percent in the first half of 1998 and has stayed low since then. However, it started raising in the decade of 20 s. In our study we will beak into two periods in order to find out whether there is stability or not. The results of study can be express as:

\section{The period of 1995Q1-2002Q2}

$\mathrm{CPI} 1=-519.8966475+35.0751438^{\star} \mathrm{LM} 21+30.3497092^{\star} \mathrm{LNEX} 1+[$ $\operatorname{AR}(1)=0.4030732445]$

$$
\begin{aligned}
& \mathrm{Se}=\left(\begin{array}{llll}
(60.21990) & (8.477368) & (8.099753) & (0.219053)
\end{array}\right. \\
& \mathrm{t}=\quad \begin{array}{llll}
(-8.633303) & (4.137504) & (3.746992) & (1.840071)
\end{array} \\
& \mathrm{n} 1=21 \text { observations after adjustments }
\end{aligned}
$$

R-squared $=0.967749 ; \mathrm{RSS1}=256.3921 ; \mathrm{F}$-statistic $=170.0387$.

\section{The period of 2003Q3-2004Q4}

CPI2 $=-605.8891237+83.80639366^{*}$ LM22 $+9.764379148^{*}$ LNEX $2+[$ $\operatorname{AR}(1)=0.227024803]$

$$
\begin{aligned}
& \mathrm{Se}=(665.0433) \quad(110.9730) \quad(9.370922) \quad(0.275093) \\
& \mathrm{t}=(-0.911052)(0.755196)(1.041987) \quad(0.825266)
\end{aligned}
$$

n2=17 observations after adjustments.

\begin{tabular}{|c|c|c|c|c|c|c|c|c|c|c|c|c|c|}
\hline $\mathbf{R} \mathbf{u}_{i}$ & Rex & $\mathbf{d}_{\mathrm{li}}$ & $d^{2}{ }^{2}$ & $\mathrm{Rm}_{2}$ & $d_{2 i}$ & $d^{2}{ }_{2 i}$ & $\mathbf{R} \mathbf{u}_{i}$ & Rex & $d_{\mathrm{li}}$ & $\mathbf{d}^{2}{ }_{1 i}$ & $\mathrm{Rm}_{2}$ & $d_{2 i}$ & $d^{2}{ }_{2 i}$ \\
\hline 9 & 40 & -31 & 961 & 40 & -31 & 961 & 30 & 18 & 12 & 144 & 20 & 10 & 100 \\
\hline 15 & 39 & -24 & 576 & 39 & -24 & 576 & 1 & 21 & -20 & 400 & 19 & -18 & 324 \\
\hline 32 & 38 & -6 & 36 & 36 & -4 & 16 & 37 & 19 & 18 & 324 & 17 & 20 & 400 \\
\hline 36 & 37 & -1 & 1 & 37 & -1 & 1 & 20 & 16 & 4 & 16 & 18 & 2 & 4 \\
\hline 12 & 36 & -24 & 576 & 38 & -26 & 676 & 8 & 15 & -7 & 49 & 16 & -8 & 64 \\
\hline 16 & 35 & -19 & 361 & 35 & -19 & 361 & 3 & 17 & -14 & 196 & 15 & -12 & 144 \\
\hline 33 & 34 & -1 & 1 & 33 & 0 & 0 & 40 & 14 & 26 & 676 & 14 & 26 & 676 \\
\hline 25 & 33 & -8 & 64 & 32 & -7 & 49 & 39 & 13 & 26 & 676 & 13 & 26 & 676 \\
\hline 6 & 28 & -22 & 484 & 34 & -28 & 784 & 21 & 12 & 9 & 81 & 12 & 9 & 81 \\
\hline 7 & 32 & -25 & 625 & 31 & -24 & 576 & 29 & 11 & 18 & 324 & 11 & 18 & 324 \\
\hline 27 & 31 & -4 & 16 & 30 & -3 & 9 & 19 & 10 & 9 & 81 & 10 & 9 & 81 \\
\hline 34 & 30 & 4 & 16 & 24 & 10 & 100 & 17 & 9 & 8 & 64 & 9 & 8 & 64 \\
\hline 14 & 29 & -15 & 225 & 29 & -15 & 225 & 28 & 7 & 21 & 441 & 8 & 20 & 400 \\
\hline 2 & 27 & -25 & 625 & 27 & -25 & 625 & 18 & 8 & 10 & 100 & 7 & 11 & 121 \\
\hline 31 & 26 & 5 & 25 & 26 & 5 & 25 & 13 & 6 & 7 & 49 & 6 & 7 & 49 \\
\hline 23 & 25 & -2 & 4 & 25 & -2 & 4 & 5 & 5 & 0 & 0 & 5 & 0 & 0 \\
\hline 11 & 23 & -12 & 144 & 28 & -17 & 289 & 26 & 3 & 23 & 529 & 4 & 22 & 484 \\
\hline 35 & 24 & 11 & 121 & 23 & 12 & 144 & 38 & 4 & 34 & 1156 & 3 & 35 & 1225 \\
\hline 10 & 22 & -12 & 144 & 22 & -12 & 144 & 24 & 2 & 22 & 484 & 2 & 22 & 484 \\
\hline 4 & 20 & -16 & 256 & 21 & -17 & 289 & 22 & 1 & 21 & 441 & 1 & 21 & 441 \\
\hline & & & & & & & & & & 11492 & & & 11996 \\
\hline
\end{tabular}

R-squared $=0.813054 ;$ RSS2 $=171.0886 ;$ F-statistic $=18.84624$

Then

$\hat{\sigma}_{1}^{2}=\frac{R S S_{1}}{n_{1}-4}=\frac{256.3921}{4}=64.09803 ; \hat{\sigma}_{2}^{2}=\frac{R S S_{2}}{n_{2}-4}=\frac{171.0886}{4}=42.77215$

and $F=\frac{\hat{\sigma}_{1}^{2}}{\hat{\sigma}_{2}^{2}}=\frac{64.09803}{42.77215}=1.49859$, follows the distribution $\mathrm{F}_{(\mathrm{n} 1-\mathrm{k}, \mathrm{n} 2-}$ $\mathrm{k})=\mathrm{F}_{(13,17)}=2.345$

Table 4: Rank correlation test of heteroskedasticity. 
We can see that $\mathrm{F}<\mathrm{F}_{\mathrm{c}}$ then we cannot reject the null and we can use the Chow test.

We have $\mathrm{R}_{\mathrm{UR}}=\mathrm{RSS}_{1}+\mathrm{RSS}_{2}=256.3921+171.0886=427.4807$ with $\mathrm{df}=\left(\mathrm{n}_{1}+\mathrm{n}_{2}-2 \mathrm{k}\right)=(21+17)-2^{*} 4=30$

$F=\frac{\left(R S S_{R}-R S S_{U R}\right) / k}{R S S_{U R} /(n 1+n 2-2 k)} F_{k, n 1+n 2-2 k}=F=\frac{(498.2149-427.4807) / 4}{427.4807 /(30)}=\frac{17.68355}{14.24936}=1.24101$.

$F_{k, n 1+n 2-2 k},=F_{4,30}=2.69$ excesses the computed $\mathrm{F}$, we can therefore fail in rejecting the null hypothesis that means there is no structure change or break.

\section{Test for Specification Errors}

One of the assumptions of the class linear regression model is that the regression model used in the analysis is correctly specified. If the model is not correctly specified, we will encounter the problem of model specification error or bias. Thus, in the case of the inflation model, we will test for this assumption. Ramsey's RESET test is one of general test for specification error. Assume we introduce the dependent variable CPI in some form as regressor, it should increase $\mathrm{R}^{2}$.

$$
C P I_{t}=\gamma_{0}+\gamma_{1} \ln (M 2)_{t}+\gamma_{2} \ln (E x)_{t}+\gamma_{3} \ln (C \hat{P} I)_{t}+u_{t} .
$$

If the increase in $\mathrm{R}^{2}$ is statistically significant on the basic of F-test, it will suggest that the model is mis-specified.

We now run the regression of model (1), the result obtained as (Appendix 6):

$\mathrm{CPI}=-278.4594666-4.407466826^{*} \mathrm{LNEX}+8.725926792^{*} \mathrm{LNM} 2+32$ $.52046365^{\star} \mathrm{LN}(\mathrm{CPI}) \mathrm{t}^{2}+[\mathrm{AR}(1)=0.2675383112]$

with $\mathrm{R}^{2}=0.979413 ; \mathrm{d}=1.753358$

Then, $F=\frac{\left(R_{\text {new }}^{2}-R_{\text {old }}^{2}\right) / d f 1}{\left(1-R_{\text {new }}^{2}\right) / d f 2}=\frac{(0.979412-0.977752) / 1}{(1-0.979413) / 34}=2.743187$.

Where, $\mathrm{df}_{1}$ is the number of new regressor; $\mathrm{df}_{2}=\mathrm{n}$ - number of parameters in the new model Choose level of significant $\alpha=5 \%$, then $F c=F_{d f 1, d f 2}^{\alpha}=F_{1,34}^{0.05}=4.125$. Obviously, Fc is exceeds the computed $\mathrm{F}$ that indicates that the model is not mis-specified.

As another test for omitted variable is Wald test. This is a really common and regularly used restriction test, but is better for large samples. In this study, because of limited observation, we will not employ the test here. We therefore use other method which will be shown in the next part (F-test for incremental variable).

\section{Test for an Incremental of an Explanatory Variable}

In previous part, we also tested successfully for specification error. However, some economists argue that increase in bank interest rates has pushed up inflation. In fact, consumers and investors will face higher borrowing costs as interest rate increases. As consequently that will push up price at higher level. In the case of Mongolia, we will assume that interest rate also affects inflation, we then add it to the model to find out whether it has any effect on inflation:

$$
\mathrm{CPI}_{\mathrm{t}}=\gamma_{0}+\gamma_{1} \ln (\mathrm{M} 2)_{\mathrm{t}}+\gamma_{2} \ln (\mathrm{Ex}) \mathrm{t}+\gamma_{3} \ln (\operatorname{Int})_{\mathrm{t}}+\mathrm{u}_{\mathrm{t}}
$$

Run regression we have (Appendix 7):

$\mathrm{CPI}=-453.1666117+16.02227963^{\star} \mathrm{LNM} 2+1.065209573^{\star} \mathrm{LNINT}+5$ $0.08061664^{\star} \mathrm{LNEX}+[\mathrm{AR}(1)=0.3356005178]$

with $\mathrm{R}^{2}=0.977935$; F-statistic $=376.7226 ; \mathrm{d}=1.826516$

From the initial model, we have

$\mathrm{CPI}=-428.761292+15.70320991^{\star} \mathrm{LOG}(\mathrm{M} 2)+47.56844772{ }^{\star} \mathrm{LOG}(\mathrm{E}$
$\mathrm{X})+[\operatorname{AR}(1)=0.3115417286]$

$$
\begin{array}{llll}
\mathrm{Se}=(-20.19801) & (2.173094) & (5.187411) & (0.159050) \\
\mathrm{t}=(21.22790) & (7.226200) & (9.169978) & (1.958765) \\
\mathrm{P}=(0.0000) & (0.0000) & (0.0000) & (0.0581) .
\end{array}
$$

R-squared $=0.977752 ; \mathrm{df}=39 ;$ F-statistic $=512.7198$

$F=\frac{\left(R_{\text {new }}^{2}-R_{\text {old }}^{2}\right) / d f_{1}}{\left(1-R_{\text {new }}^{2}\right) / d f_{2}}$ Where, df1is the number of new regressor, df2 is the number of parameters in the new model

$$
F=\frac{(0.977935-0.977752) / 1}{(1-0.977935) / 34}=\frac{0.00183}{0.000649}=0.281985<F_{1,34}{ }^{0.05}=4.125 \text { It is clearly }
$$

seen that Interest rate does not affect inflation in Mongolia. Therefore, we will get the interest rate out of the model.

\section{Testing the Overall Significance of the Multiple Regression using F Test}

According to Gujarati (2004: 257), to test overall significance of the regression, $\mathrm{F}$ test can be employed to test the null hypothesis that all slope coefficients, $\gamma_{1}$ and $\gamma_{2}$, are simultaneously zero (H0). Alternatively, one or all of those will not be equal to zero $\left(\mathrm{H}_{1}\right)$.

Recall our regression result (Appendix 8):

$\mathrm{CPI}=-428.761292+15.70320991^{\star} \mathrm{LOG}(\mathrm{M} 2)+47.56844772{ }^{\star} \mathrm{LOG}(\mathrm{E}$ $\mathrm{X})+[\mathrm{AR}(1)=0.3115417286]$
$\mathrm{Se}=(-20.19801)(2.173094)$
$(5.187411)(0.159050)$
$\mathrm{t}=(21.22790)$
$(7.226200)$
$(9.169978)(1.958765)$
$\mathrm{P}=(0.0000)$
$(0.0000)$
$(0.0000)$
$(0.0581)$

R-squared=0.977690; $\mathrm{df}=39 ; \mathrm{F}$-statistic $=511.2607$

Choose level significant $\alpha=5 \%$, we have: $\mathrm{F}_{\alpha(\mathrm{k}-1, n-k)}=F_{0.05(3,36)}=2.88$.

The F statistic tells us that the estimated parameters for the regression are effective, and so under the null hypothesis that there is no relationship between money supply, exchange rate and CPI this model is well estimated. The p-value for this F statistic is practically zero. We can confidently use this as evidence to reject the null hypothesis, so this indicates that there is a relationship between money supply, exchange rate and CPI. Thus, we can confidently reject the null hypothesis that $\mathrm{M} 2$, exchange rate has no effect on CPI.

We can also express linear relationship between CPI and other estimated regressors by the graph (Figure 3 ).

\section{Testing the about Individual regression Coefficients using $\mathrm{T}$ Test}

Recall the assumption of OLS that ui follows $\mathrm{N}\left(0, \sigma^{2}\right)$ distribution to ensure that $\gamma_{1}, \gamma_{2}, \gamma_{3}$ are minimum variance estimators in the entire class of unbiased estimators or in short they are BLUE. Thus, we will apply $\mathrm{t}$-test to test hypotheses about individual partial regression 3 coefficients for our CPI model:

$$
C \hat{P}_{t}=\gamma+\gamma_{1} \ln (M 2)_{t}+\gamma_{2} \ln (E x)_{t}+A R(1)+u_{t} .
$$

Since, CPI, M2 and Ex are expected to be positively related as we mentioned in the previous part. We should therefore use right tail-test, that is:

Assume that under the null hypothesis $\mathrm{H}_{\mathrm{o}}: \gamma_{1} \leq 0$, alternately $\mathrm{H}_{1}: \gamma_{1}$ $>0$ (other variables hold constant). 

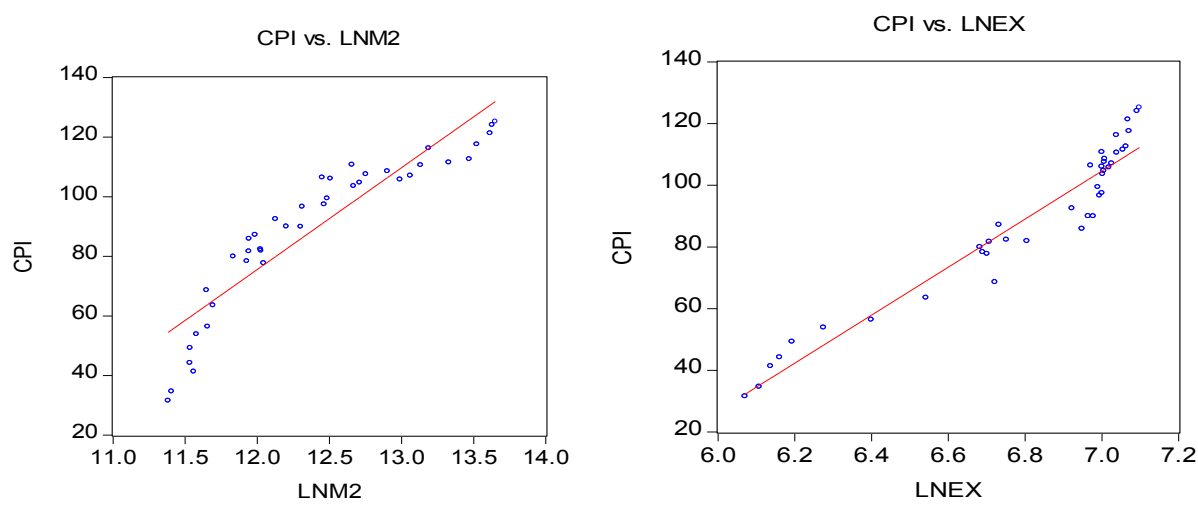

Figure 3: Linear relationship between $\mathrm{M} 2$, exchange rate and $\mathrm{CPI}$.

$$
t=\frac{\hat{\gamma}_{1}-\gamma_{1}}{\operatorname{Se}\left(\hat{\gamma}_{1}\right)}=\frac{15.70321-0}{2.173094}=7.22620 .
$$

Choose level of significant $\alpha=5 \%$, we have: $\mathrm{t}_{0.025,35}=2.0315$, is smaller in comparison with the computed t. Thus, we can be comfortable to reject the null hypothesis that there is no relationship between CPI and $M 2$. Actually we can look at $P$ value is statistically significant $(P=0)$.

Similarity, we also test for the relation between CPI and Exchange rate. With $\mathrm{P}$ value equals to zero and t-test excesses the critical $\mathrm{t}_{0.025,35}$, we can then conclude that CPI and Ex have a positive relationship.

\section{Test for the Equality of Two Regression Coefficients}

Actually, testing the equality of two regression coefficients is of practical important. Under the null hypothesis we assume that two coefficients are identical that means the coefficients (or elasticity in the case of variables expressed in logarithmic form) of money supply and exchange rate is the same.

$\mathrm{CPI}=-428.761292+15.70320991^{\star} \mathrm{LOG}(\mathrm{M} 2)+47.56844772{ }^{\star} \mathrm{LOG}(\mathrm{E}$ $\mathrm{X})+[\mathrm{AR}(1)=0.3115417286]$

$$
\begin{aligned}
& \mathrm{Se}=\left(\begin{array}{llll}
(-20.19801) & (2.173094) & (5.187411) & (0.159050)
\end{array}\right. \\
& \mathrm{t}=(21.22790) \quad(7.226200) \quad(9.169978) \quad(1.958765) \\
& \mathrm{R} 2=0.977719 \quad \operatorname{Cov}\left(\hat{\gamma}_{1}, \hat{\gamma}_{2}\right) \quad-4.612292
\end{aligned}
$$

Now we should test: $\mathrm{H}_{0}: \gamma_{1}=\gamma_{2}$ or $\gamma_{1}-\gamma_{2}=0$

Alternatively, $H_{1}: \gamma_{1} \neq \gamma_{2}$. Where

Follows the classical assumption, we have: $t=\frac{\left(\hat{\gamma}_{1}-\hat{\gamma}_{2}\right)-\left(\gamma_{1}-\gamma_{2}\right)}{\operatorname{Se}\left(\hat{\gamma}_{1}-\hat{\gamma}_{2}\right)}$,

$$
\begin{aligned}
& \operatorname{Se}\left(\hat{\gamma}_{1}-\hat{\gamma}_{2}\right)=\sqrt{\left(\operatorname{var}\left(\hat{\gamma}_{1}\right)+\operatorname{Var}\left(\hat{\gamma}_{2}\right)-2 \operatorname{Cov}\left(\hat{\gamma}_{1}, \hat{\gamma}_{2}\right)\right.}=\sqrt{(2.173094)^{2}+(5.87411)^{2}-2 *(-4.612292)} \\
& t=\frac{(15.703247 .5684)-0}{6.3918}=-4.9853 .
\end{aligned}
$$

Choosing the significant level $\alpha=5 \%$, we have $t_{c}=t_{0.05,39-4}=2.0315$. For $35 \mathrm{df}$, the absolute value $\mathrm{t}$ observed excesses the $\mathrm{t}$ value and the $P$ value is extremely small, thus, we can reject the null hypothesis that coefficients of money supply and exchange rate are identical.

\section{Confidence Intervals for Coefficients}

Because of sampling fluctuations, a single estimate is likely differ from the true value, although in repeated sampling its mean value is expected to be equal to the true value. Therefore, instead of relying on the point estimated alone, we may construct an interval around the point estimator such as for coefficient $\gamma_{1}$ and $\gamma_{2}$. Under the assumption of OLS, all coefficients follow normal distribution. We can then use $t$ distribution to establish the confidence interval:

$$
\begin{aligned}
& \operatorname{Pr}\left[-t_{\alpha / 2} \leq t=\frac{\left(\hat{\gamma}_{i}-\gamma_{t}\right)}{\operatorname{Se}(\hat{\gamma})} \leq t_{\alpha / 2}\right]=1-\alpha \quad \text { Or } \\
& \operatorname{Pr}\left[\hat{\gamma}_{i}-t_{\alpha / 2} * \operatorname{Se}\left(\hat{\gamma}_{i}\right) \leq \gamma_{i} \leq \hat{\gamma}+\operatorname{Se}\left(\hat{\gamma}_{i}\right) * t_{\alpha / 2}\right]=1-\alpha .
\end{aligned}
$$

Choosing the significant level $\alpha=5 \%$, that is, 95\% confidence coefficient then we have: $t_{c}=t_{0.025,39-4}=2.0315$, substitute;

The confidence interval for $\gamma_{1}: \operatorname{Pr}\left[47.45894-2.0315^{\star} 5.194420 \leq \gamma_{1}\right.$ $\leq 47.45894+2.0315^{\star} 5.194420$ ]

$36.90648 \leq \gamma_{1} \leq 58.0114$

This interval is the probability that the specified fixed interval includes $\gamma_{1}$

The confidence interval for $\gamma_{2}$ :

$\operatorname{Pr}\left[15.76220-2.0315^{\star} 2.177666 \leq \gamma_{2} \leq 15.76220+2.0315^{\star} 2.177666\right]$

$11.33827 \leq \gamma_{2} \leq 20.18613$.

Again the interval is the probability that the specified fixed interval includes $\gamma_{2}$.

In short, given the confidence coefficient of $95 \%$, in the long run, in 95 out of 100 cases interval like $(36.90648 ; 58.0114)$ and (11.33827; 20.18613) will contain the true $\gamma_{1}$ and $\gamma_{2}$ respectively.

\section{Discussion}

Based on the econometric techniques, the series of tests have been done taking into account of the inflation model. The equation shows that inflation is strongly affected by exchange rate and money growth changes and that the pass-through is fast. Changes inflation of the prior period also has a significant impact on current inflation, but this effect takes longer to work its way through the economy than money supply and exchange rate changes. Results of the tests suggest that we have found extremely high correlation between money growth, exchange rate and inflation. The model points to a dominant role of monetary policies in the behaviour of inflation and shows a low persistence of inflation in Mongolia. Both factors contributed to the observed behaviour of inflation.

\section{Conclusion}

Our results are based on limited money, exchange rate and CPI data from 1995-2004. The econometric results show that it is feasible to estimate robust money supply, exchange rate and inflation equations 
for Mongolia. The model expresses inflation as a function of money, and the exchange rate, and may be interpreted as portraying equilibrium in the goods market. In fact, the dynamics of inflation are strongly affected by current exchange rate changes and money growth that implications and ultimately designing better monetary policies and institutions. Our hope is that this study will stimulate research on models of monetary standards and encourage efforts to obtain better data on the experiences of countries under alternative monetary standards.

\section{References}

1. Makiw G (2003) Macroeconomics.
2. Dwyer P, Hafer RW (1999) Are money growth and Inflation related?

3. Rolnick AJ, Weber WE (1996) Money, Inflation, and Output Under Fiat and Commodity Standards. Journal of Political Economy.

4. Torsten S (2000) Can Monetary Policy Be Effective During Transition?-Lessons from Mongolia. Finance and development 37: 44.

5. Siliverstovs B, Bilan O (2005) Modeling Inflation Dynamics in Transition Economies: The Case of Ukraine. Eastern European Economics 43: 66-81.

6. Fujiki $\mathrm{H}$ (1998) Japanese money demand: Evidence from regional monthly data. Japan and World Economy 11: 375-393.

7. Hallwood CP, MacDonald R (2000) International Money and Finance. Third edition. 